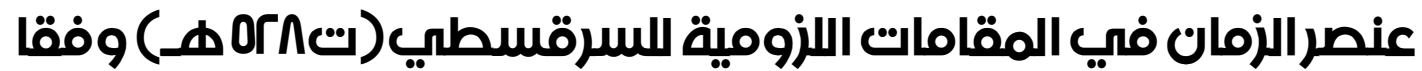 لمنفج (جيرارجينيته)

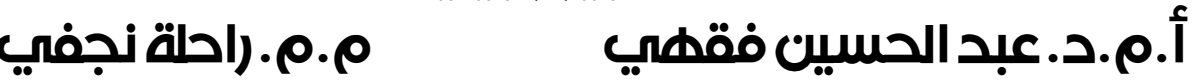 إيران - جامعة طهران / قسم الفة العربية afeghhi@ut.ac.ir

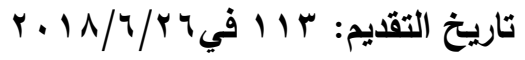

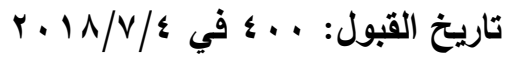

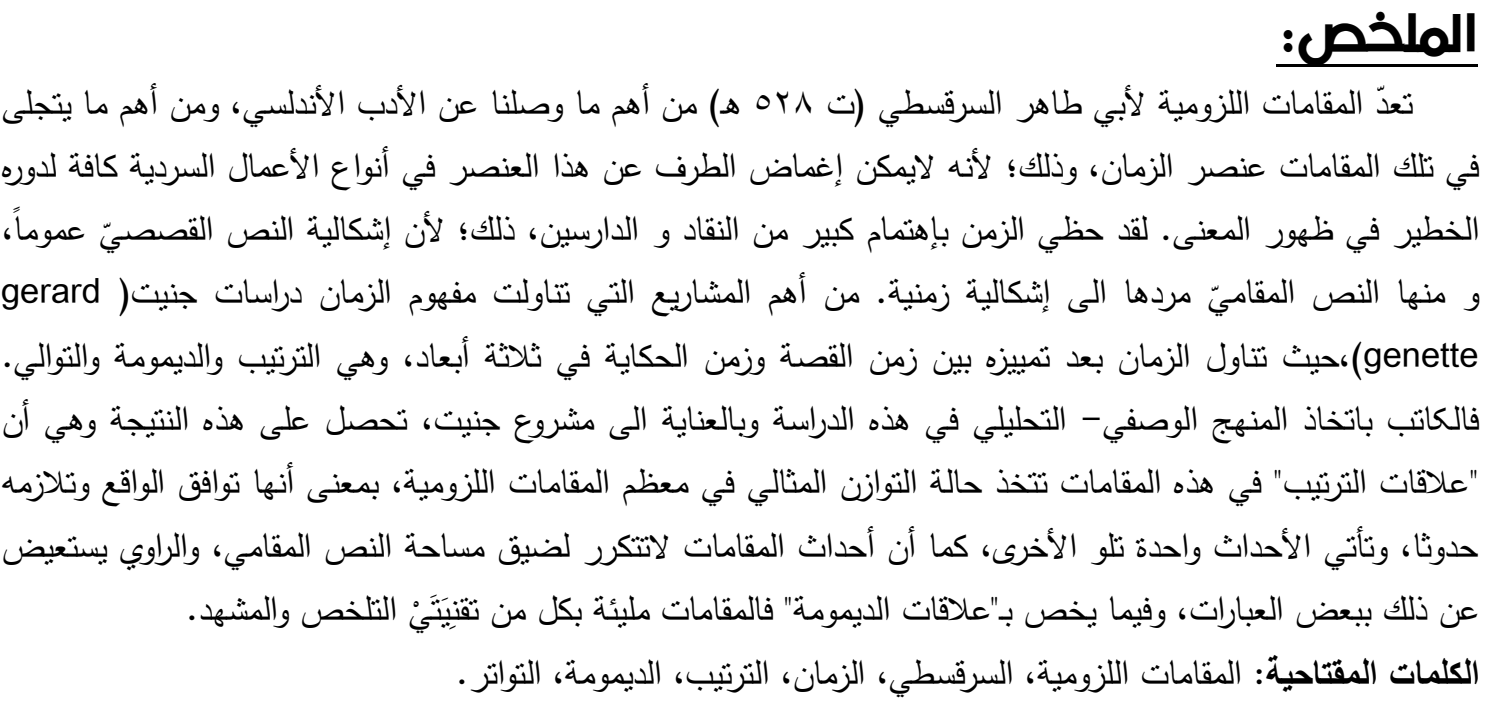

The study of time element in Maghamate Lozumiyeh by Abu Taher

Serghesti according to Gerard Genette

Assist. prof. Dr. Abdolhossain Feghhi

Assist. teacher: Raheleh Najafi

Iran - University of Tehran - Department of Arabic Language and

Literature

afeghhi@ut.ac.ir

\begin{abstract}
:
Maghamate Lozumiyeh by Abu Taher Serghesti is one of the most important literary sources of Andalusia literature and time element is one of the most striking elements that is revealed in these Maghamat. Therefore, this element is significant due to an important role in narrated works in revealing the meaning. That is why it has attracted many critics and researchers' attention. Hence, the basic issue in narrated context, is the time problem. Gérard Genette's research is one of the most important scientific projects in this field that distinguished in three dimensions between time of the story and the anecdote and they are: order, continuity and sequence. The author relying on the analytical method and with regard to Genette and his followers' scheme has analyzed time element in these Maghamat. From the results of this article we can conclude that in most of Maghamate Lozumiyeh, order links have got schematic balance in a way that the incidents are compatible with reality temporally. As Maghamat's incidents are not repeated because of framework's limitations and the article text size and the narrator has replaced some other expressions instead. However, comparing to continual links, Maghamat are full of two techniques of Liberating and scenery.
\end{abstract}

Key words: Maghamate Lozumiyeh, Serghesty, time, order, continuity, sequence. 
المقدمة:

لاشك أن عنصر الزمان من أصعب الموضوعات فهما وتحليلا، وأسهلها معرفة في الوقت

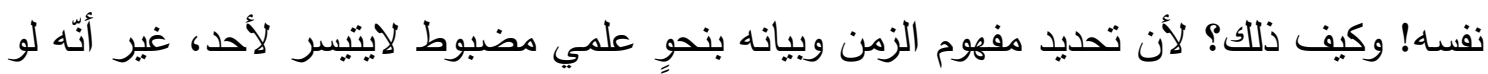

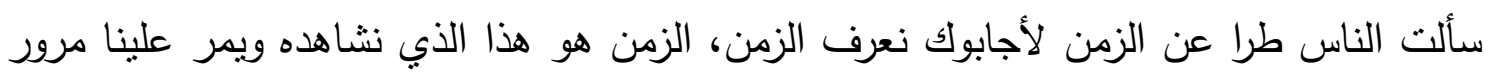

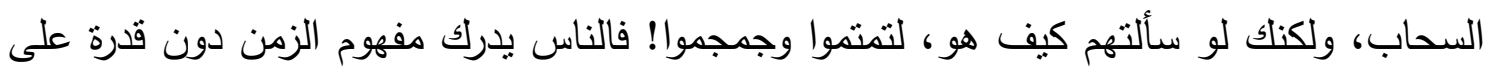
تحديد مفهومه، وعلى حد تعبير القديس أوغطيس: "فما هو الوقت إذن؟ إن لم يسألني أحد عند أنه

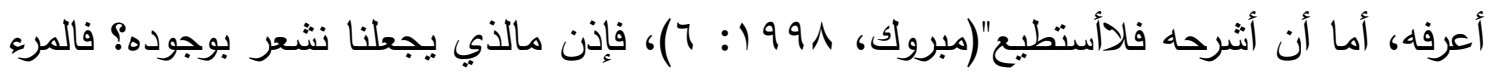

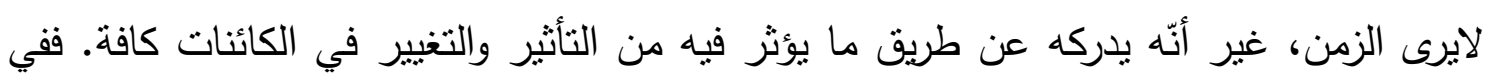

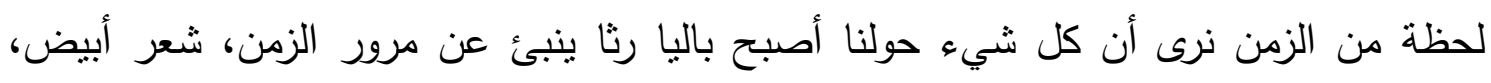

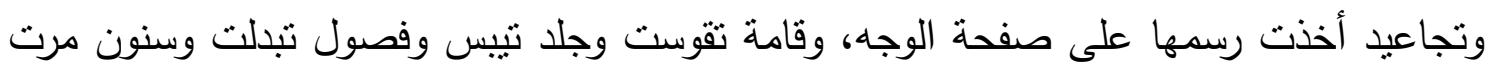

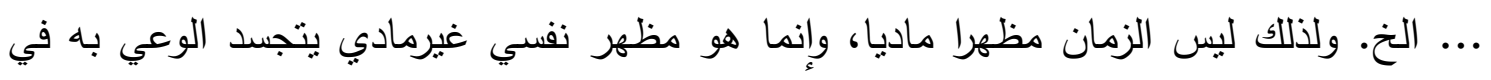

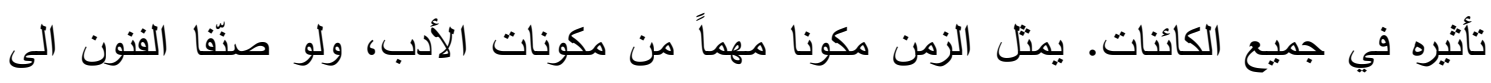
المكانية والزمانية لرتبا الأدب من ضمن الفنون الزمانية كالموسيقى مقابل الفنون المكانية كالرسم

$$
\text { والنحت و ... الخ. }
$$

ومما لاثك فيه أن مفهوم الزمان يختلف تبعا لنوع دراسته؛ لأن دراسة الزمن في الدراسات

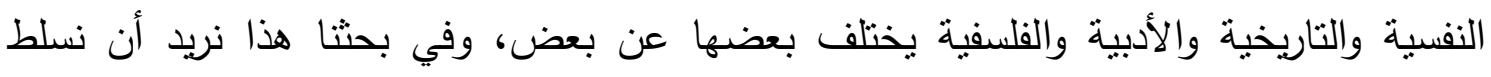

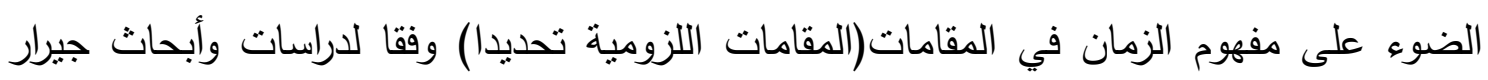
جينيت، ووفقا لتلك الدراسات في تحليل الزمان لابد من أن نركّز في مفاهيم ثلاثة في تحليل القصة

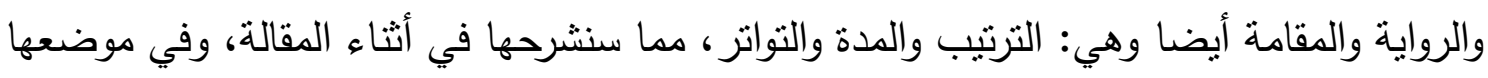
شرحا مفصلا، ونبين مدى بلورة نلك المفاهيم الثناثة في المقامات اللزومية.

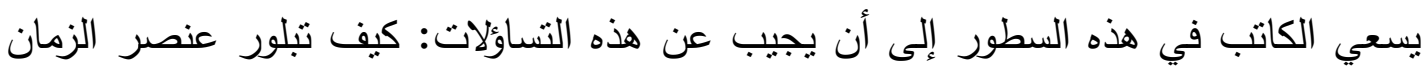
في مقامات السرقسطي؟ وكيف يمكن أن نحلّل مفهوم الزمان في مقامات السرقسطي وفقا لـقات لمقترح جينيت لتحليل عنصر الزمان في السرد والقصةٌ وهل يمكن نطبيق ذلك على فن المقامات؟ خلفية البحث:

كتبت عديد من الكتب والمقالات حول المقامات اللزومية لأبي طاهر السرقسطي، ودرستها

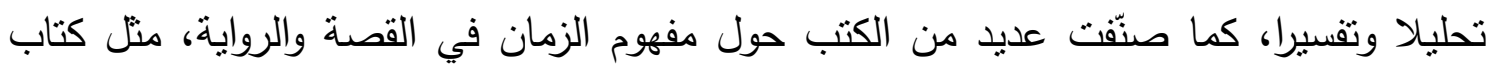

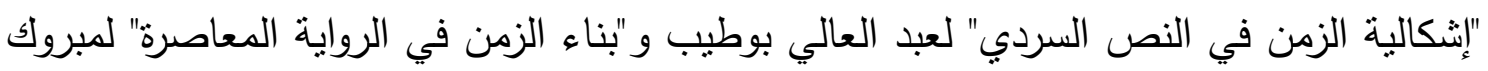

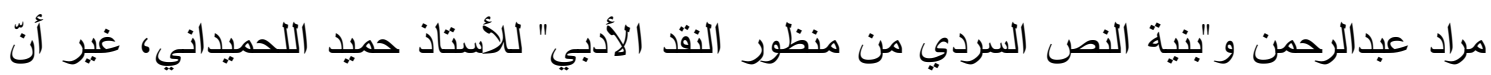
هذه الدارسات تتاولت مفهوم الزمان بنحٍِ عام في القصة والرواية، ولم تتطرق إلى عنصر التهر الزمان 
في المقامات، وأما فيما يخص المقامات؛ فحدث ولاحرج، لكثرة ما كتب عن هذا الفن البليغ في الأدب العربي، غير أنّ هذه الجهود انحصرت في بيان محسنات هذا الفن لفظيا ومعنويا، دون

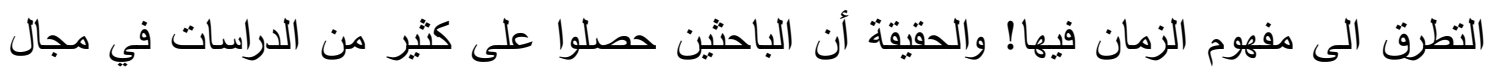

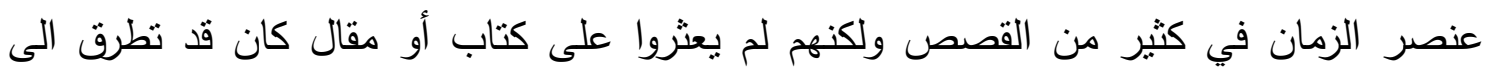

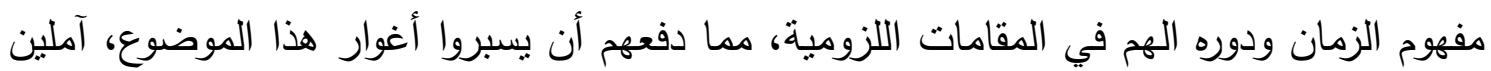
أن ينلقى هذا الجهد المتواضع بقبول الدارسين والباحثين.

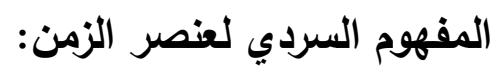

لقد حظي الزمن بإهتمام كبير من النقاد والدارسين، ومردّ هذا الإهتمام الكبير يعود الى مقولة

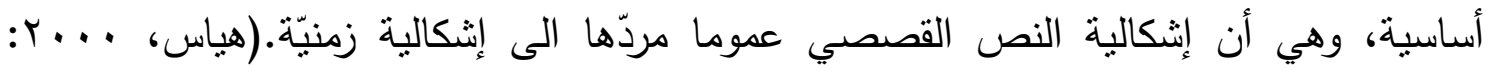

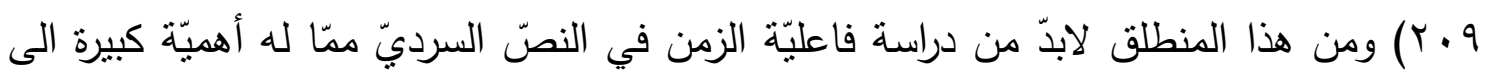

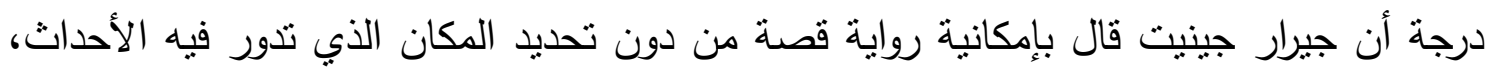

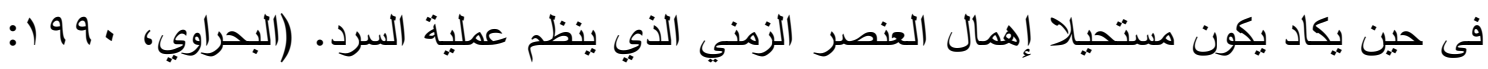

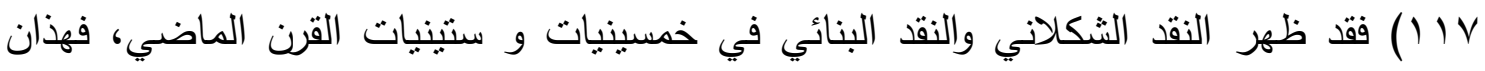
النوعان من النقد كان لهما أثز كبير على دراسات كثير من النقاد ك ـ"تودورف" و "جرارجنيت" للزمن فاعليّة كبيرة في النص السردي، فهو إحدى الركائز الأساسية التي نستند اليها العمليّة

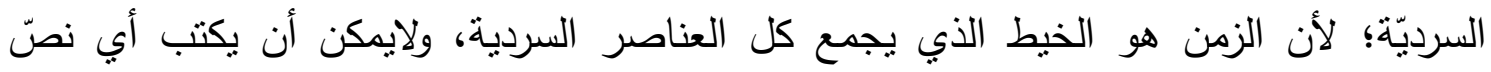

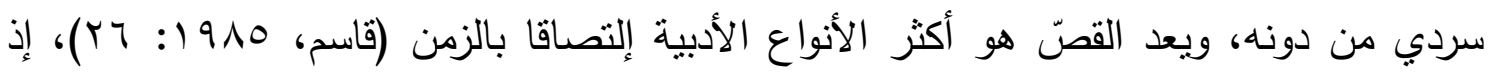

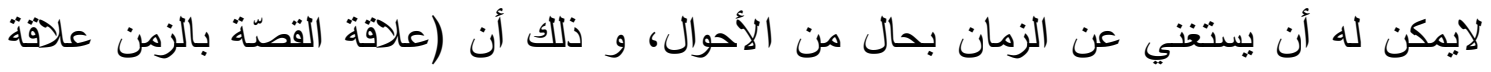

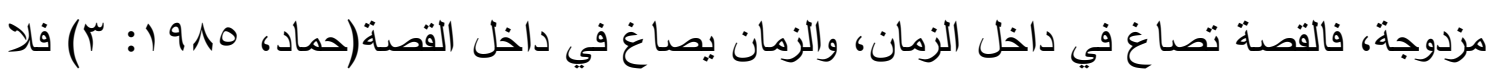
يمكن أن تسرد القصة دون تحديد زمنها. وقد اتفقت الدرسات السردية عموما على التقريق بين زمنين في القص، وهما: زمن القصة

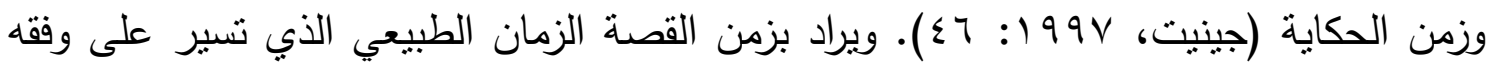

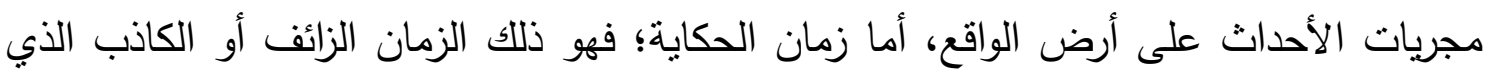
يحاول أن يقوم مقام الزمان الحقيقي في القص، ويتحكم الراوي في هذا الزمان على سير الأحداث بنفسه وعلى ما يشاء. (المصدر نفسه) مستوى بناء الزمن السردي عند جيرار جينيت:

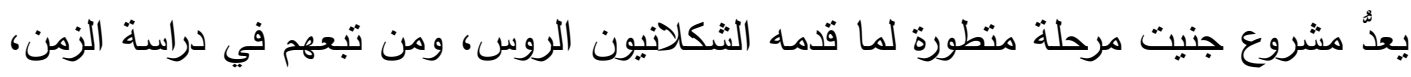

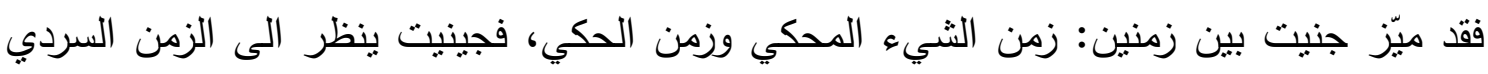

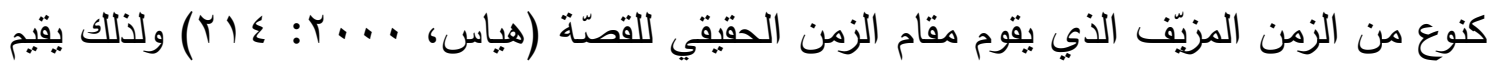


ثلاث علاقات لدراسة الزمن في ضوء العلاقة بين القصة (الزمن الحقيقي) وزمن الحكاية (الزمن المزيّة) وهي على النحو الآتي: ا : علاقات الترتيب: وتقوم على نوضيح الصلات بين الترتيب الزمني لنتابع الأحداث في القصة في أرض الواقع والتزتيب الزمني الكاذب لتتظيمها في الحكاية وهي الزمان المزيف. r علاقات التواتر : ويقصد بها العلاقات بين قدارت تكرار القصة وقدرات تكرار الحكاية.

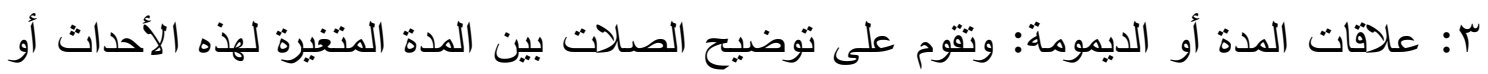
المقاطع القصصية والمدة الكاذبة (المصدر نفسه: ع ع (). وفقا للمراحل الثلاث التي تتاولها جيرار جينت نتتاول بحول الهه وقوته مدى انطباق تلك المراحل أو الو العلاقات في المقامات السرقسطية على الترتيب. أولاً/ مستوى الترتيب عند جيرار جينيت: ويعني ذلك. (الصلات بين التزتيب الزمني لتتبع الأحداث في القصة والترتيب الزمني الكاذب التبات

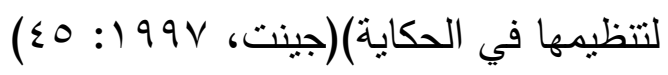
من المعروف أن مهمة الكاتب في القصة هي نتظيم الأحداث طبيعيّا وفقا لترتيبها وتنسلسلها

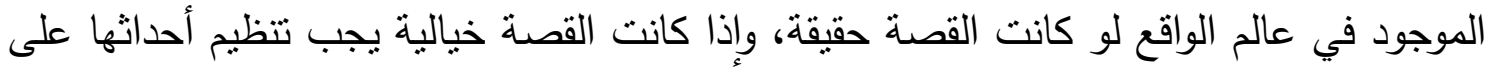

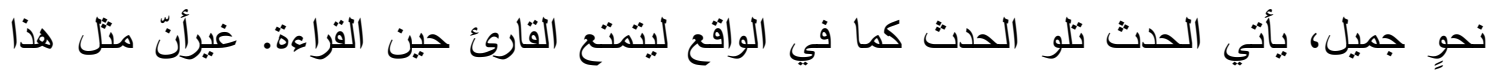

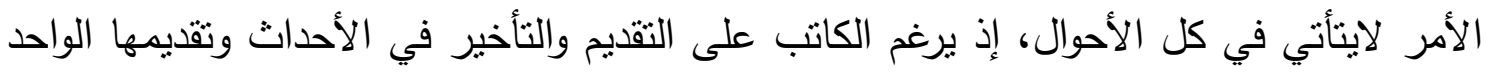

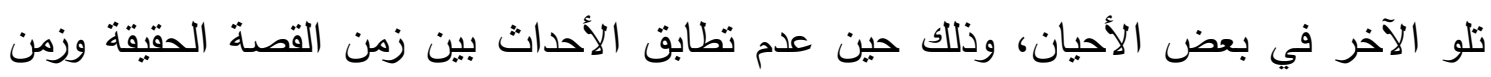

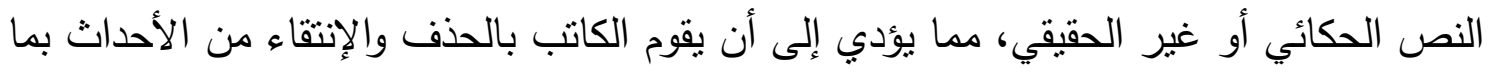

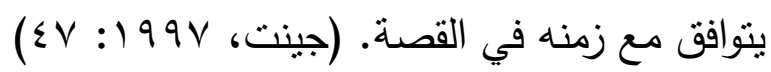
ومرد ذلك أن النص السردي هو نص سردي لاحق أو مؤجل، حيث أنّهُ لا يبدأ الا بعد إنتهاء

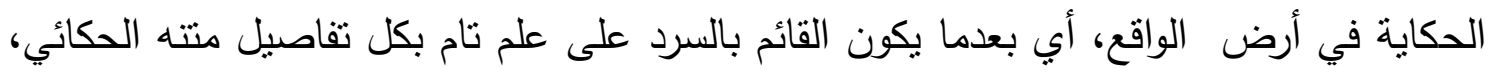

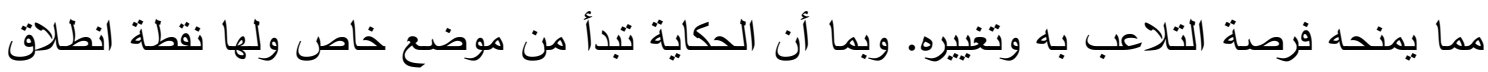

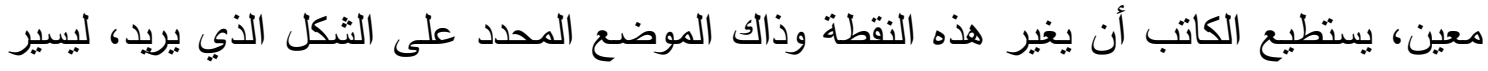

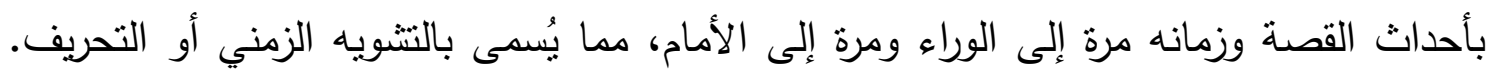

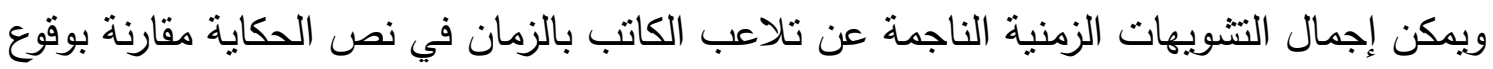

$$
\text { الاحداث في القصة (الواقع) في ثلاثة احتمالات على النحو الآتي: }
$$

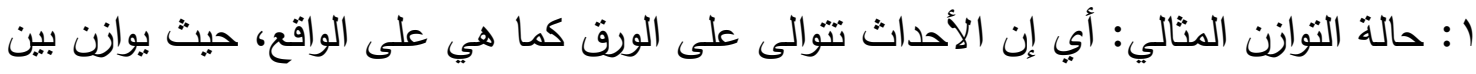

$$
\text { زمني الحكاية والسرد. }
$$


r: حالة القلب: إذ يبدأ الكاتب مبناه الحكائي من حيث ما انتهى على الواقع في رجوع تدريجي

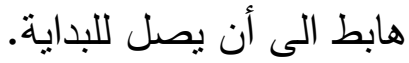
r: حالة الإنطلاق من وسط المنن الحكائي: وذلك أن يختار السرد نقطة إنطلاقه من حدث وسط

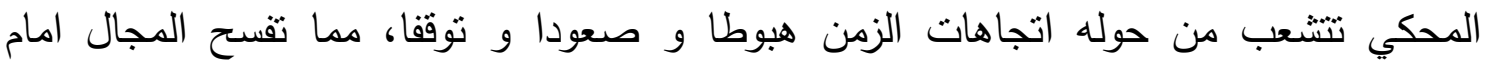

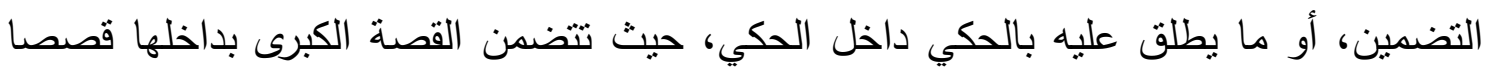

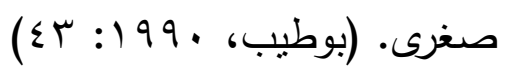

ووفقاً لما تقدّم نجد أن التزتيب في مقامات السرقسطي يتخذ الحالة الأولى في معظم مقاماته، حيث إننا نجد الأحداث تثوالي على الورق كما هي على الواقع في أكثر من تسعين بالمائة من مجمل المقامات الخمسين، ويمكن التمثيل على ذللك بالمقامة الأولى من مقاماته، وذلك بتقسيمها عن طريق التلخيص على الوحدات الآتية: | أصيب الراوي (السائب) بالفقر والمسغبة في أحد البلاد.

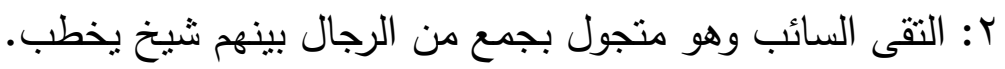

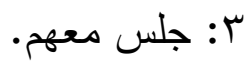
؟: طلب منه الثيخ ليقدم نفسه على الحضور . 0: عرف بنفسه للثيخ والحضور وذكر الحال التي تعتريه من الفقر بعد الغنى. 7: رحّب به الثيخ وحثّ الحضور على تقديم المال والعطايا له. V: قدم له الناس ما استطاعوا من مال وعطاء حتى إمتلات جرابه.

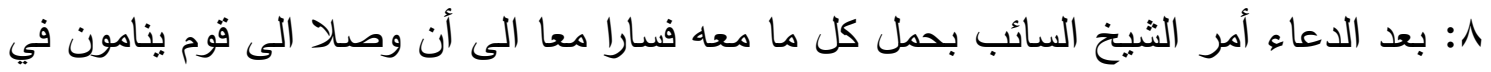
خيام وقت حلول العشاء. 9: ترك الثيخ السائب وحده بدعوى أنه يريد إكرامه. • 1: جاء القوم عليه وقاموا بضربه وطرده إلى خارج مضاربهم ظنا أنه السارق الذي بسرقه لئه ليلا.

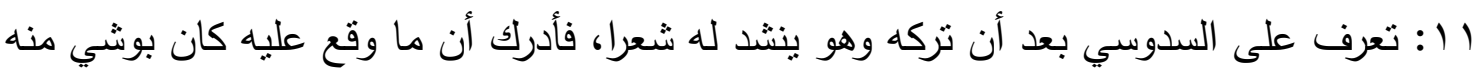

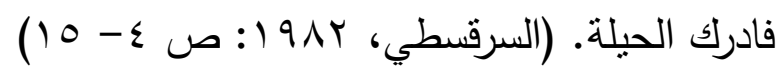
إن أحداث هذه المقامة تحدث وتتوالى في الورق وكأنها تحدث في الواقع، مما قد عبرنا عنه الته

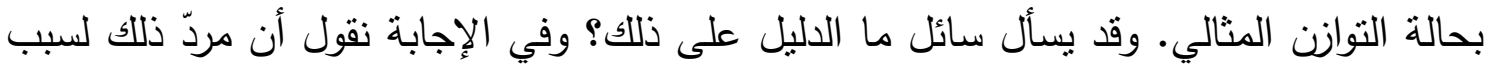

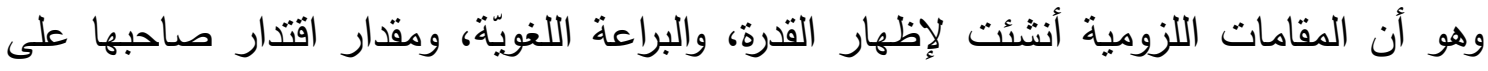
امتلاك ناصية اللغة والتفنن بها وتطويعها حسب أغراضه وأفكاره بالدرجة الأولى، ولم يكن له حاجة الى تغيير الزمان وتبديله الى الأشكال الأخرى. ونتطرّق الى المقامة الرابع عشرة أيضا لتحليل 
عنصر التزتيب فيها. يدور موضوع المقامة حول السرقة التي يقوم بها السدوسي الماهر والمقامة

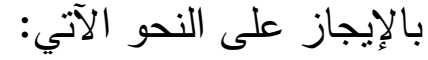
1: أقام السائب بالأنبار وهوغني.

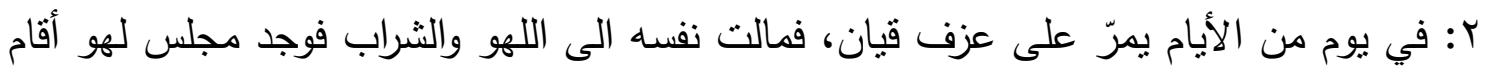
معهم لبالي وأياما. r: المشاركة في المجلس، و أن الناس قد سمعوا في إحدى صوت رجل ييكي، فأرسلوا أحدهم

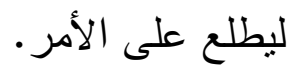
؟: أخبرهم أنه رجل واعظ فساروا إليه. 0: قام يعظهم ثم قرّر الذهاب لثيخه؛ لأنه يحتاج إليه.

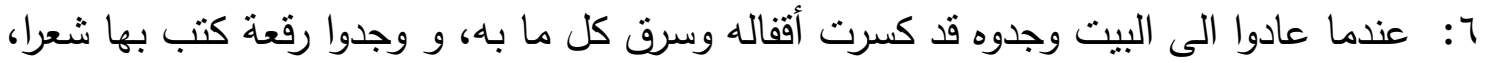

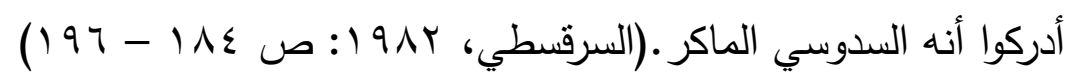

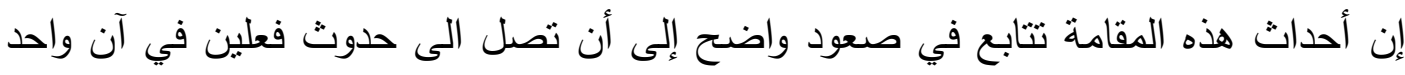

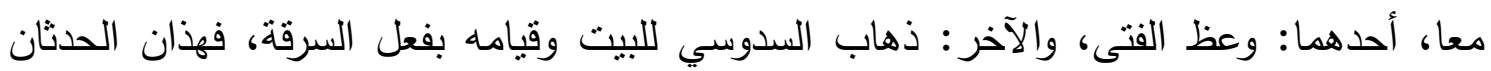

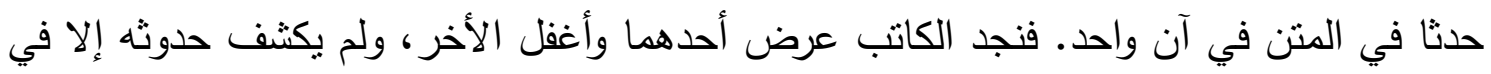

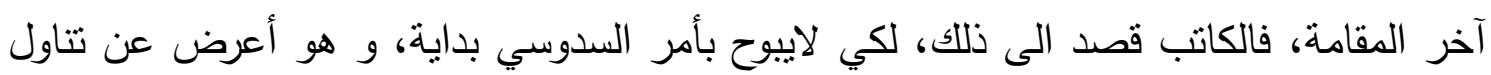

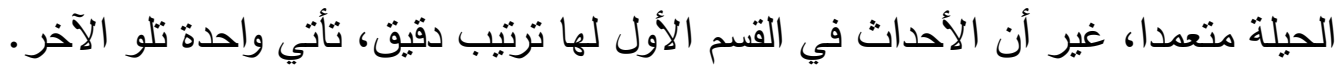

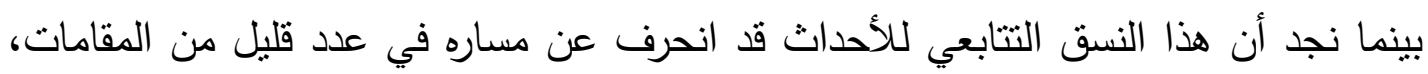

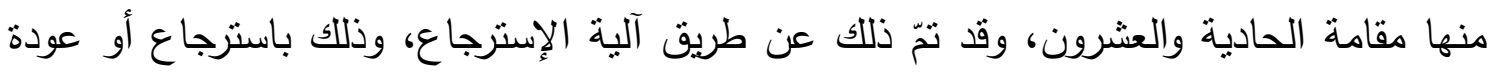

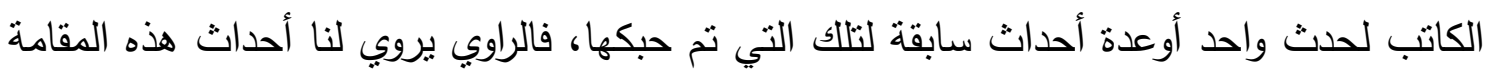
على النحو الآتي: ا : ذهاب الراوي إلى البحرين أثنعث أغبر لامؤنس ولاصديق

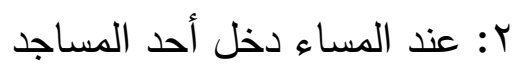
r: إلتقى الراوي بالإمام فتعرف عليه

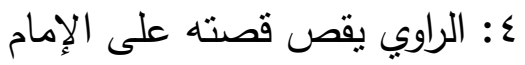

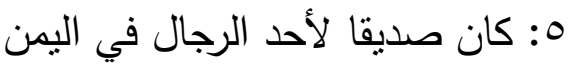

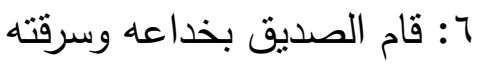
マ: هرب الراوي من اليمن الى هنا نتيجة لخداعه وجحوده

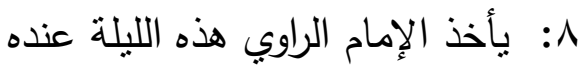
9: قام الراوي بإعطاء الإمام ما معه من درر حفظا لها لهاه وصونا 
• ا: في الصباح وجد الراوي الإمام قد سرق درره وهرب ناركا له رقعة، عرف من خلالها أنه

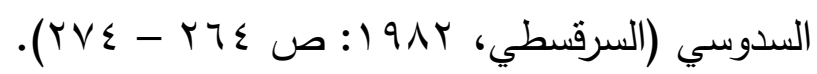

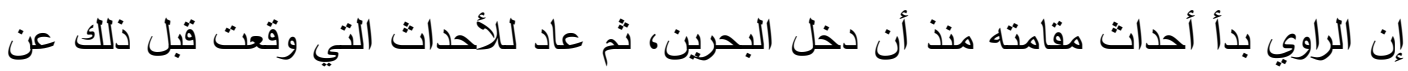

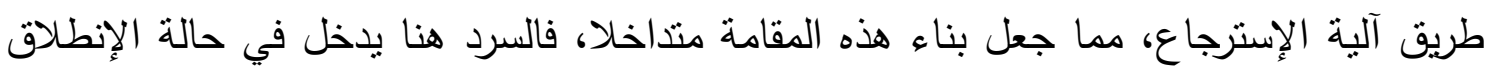
من وسط المتن. ثانيا/ مستوى التواتر : بن

يتمثّل هذا المستوى بمجموع علاقات التكرار بين النص والحكاية. فقد اهتم جينيت بهذا المستوى بهـ

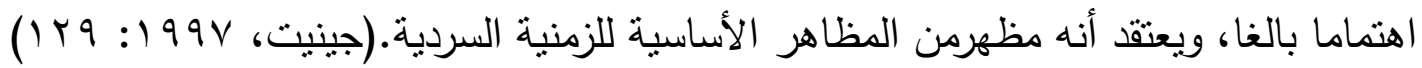
هناك علاقات تكرارية بين التخطيب والحكاية على مسنوى الأحداث بمكن التمييز بينها بالنظر

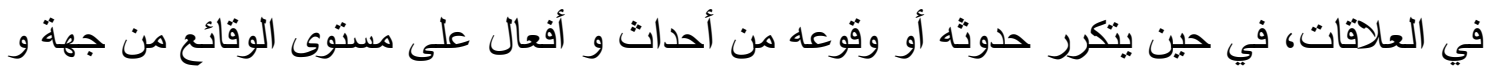

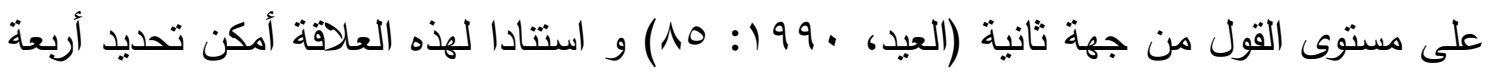

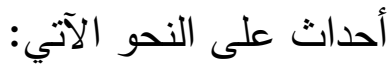
ا: الراوي يقص مرة واحدة على مستوى القول ما وقع أو حدث مرة واحدة على مستوى الوقائع مما يسمي بالحكاية التفرّدية. r: الراوي يقص عدة مرات ما جرى وقوعه أو حدوثه عدة مرات مما يسمي بالحكاية.

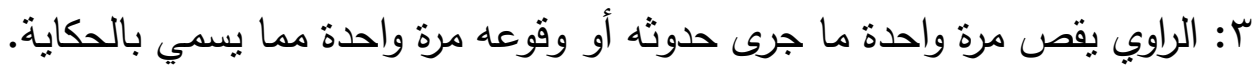

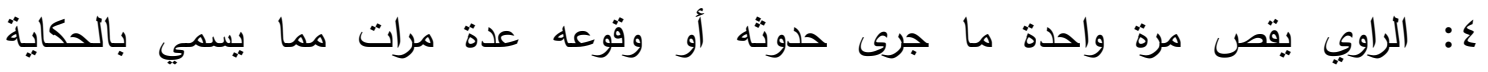

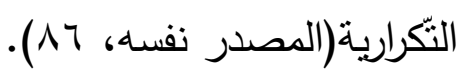
فالحالة الأولي هي التي تغلب على النص الدقامي اللزومي، إذ إن الراوي يقص مرة واحدة ما يقع مرة واحدة على مستوى الوقائع و ذللك لسببين: أ) إن البناء العام لهذه المقامات هو بناء متتابع تنوالى فيه الأحداث على الورق دلى كما هي الواقع فلا

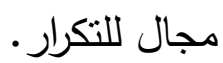
ب) إن النّص المقاميّ هو نصّ قصير نسبيّا مقارنة بالفنون السردية الأخرى التي تستخدم هذه

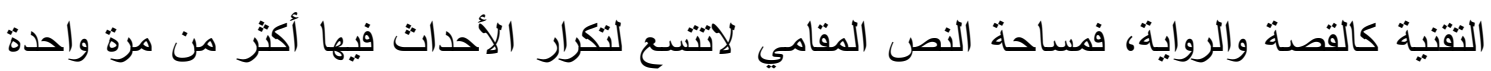

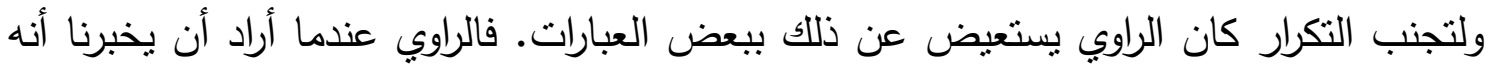
قد قصّ على الثيخ ما قد حدث معه ورفاقه فقد عبّر عنه بقوله "نحن قوم عرانا كيت

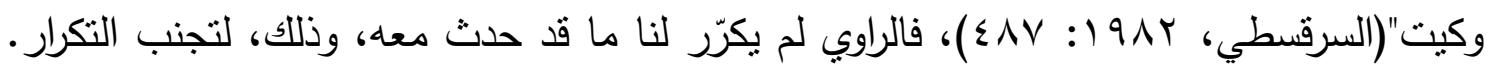

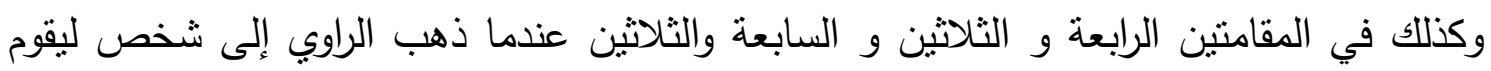
بتفسير نوم قد حَلُم به، لايكرر لنا النوم مرة ثانية عند نواجده أمام المعبر ، ولا يكرّر الحلم مرّة 
ثانية، بل يستعيض عن ذلك بقوله: " قال فنصصت له الأمر على درجة" (المصدر نفسه: •r؟؟)

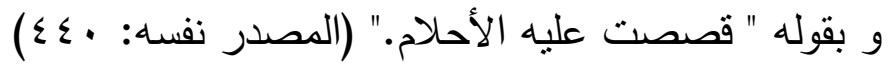
ولتجنب التكرار والإطالة في المقامة الثالثة عشرة نرى الراوي في نهايتها يخبرنا أن القوم قد ذهبوا

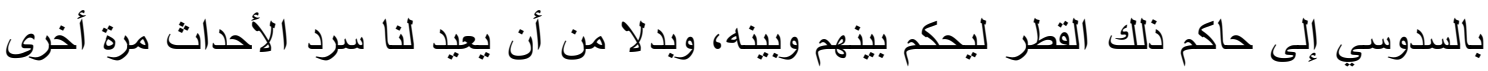

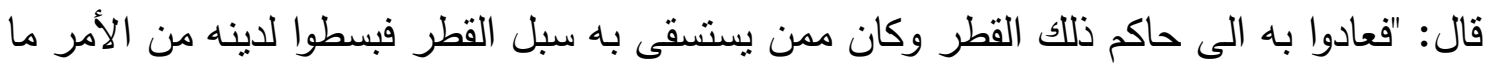

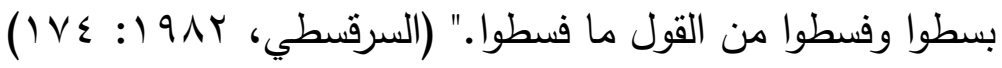

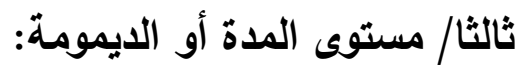
وهو مستوى يمثّل (العلاقة التي تربط زمن الحكاية الذي يقاس بالثواني والدقائق والساعات

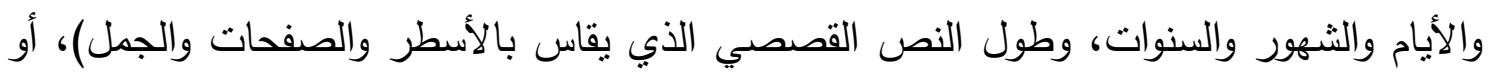

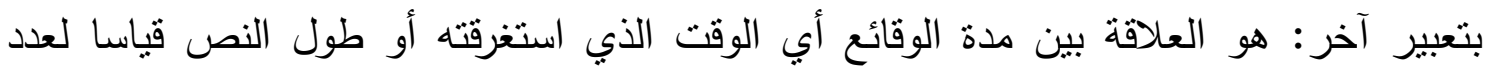

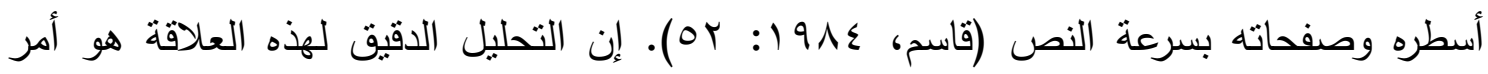

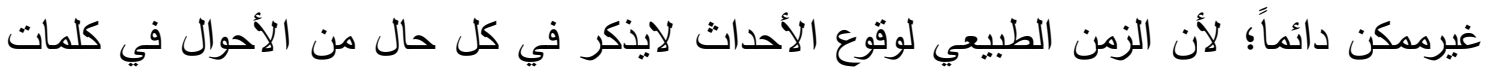

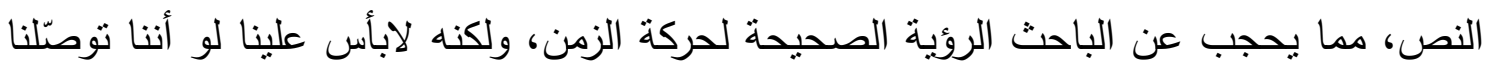

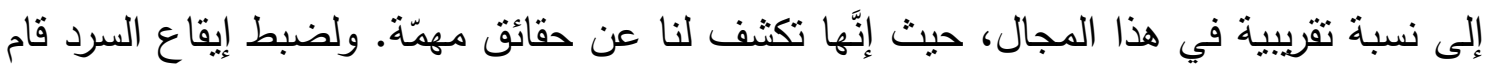

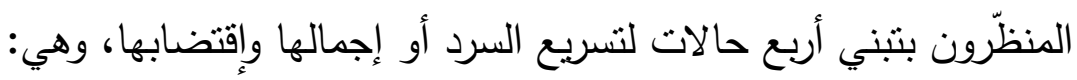

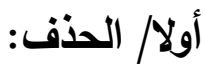

وهو تقنية تعمل على تسريع السرد، وتتمتّل في تغطية لحظات الحكاية بأكملها دون الإثشارة

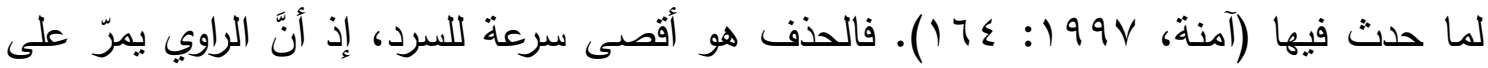

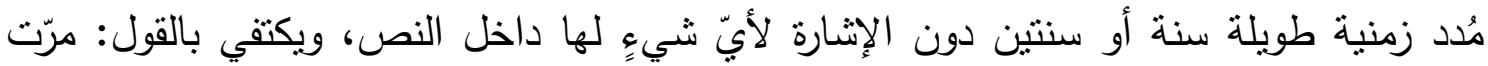

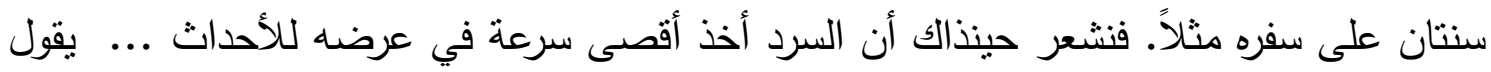

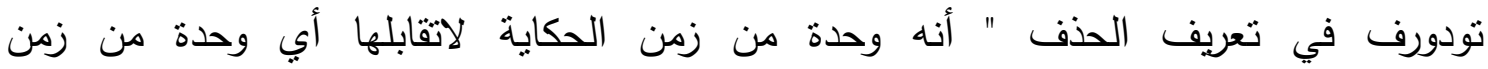
النص"(بوطيب، .99 19 إ: or) أما الحذف في المقامات اللزومية فيظهر بكثرة، وذللك ليقوم بعملية

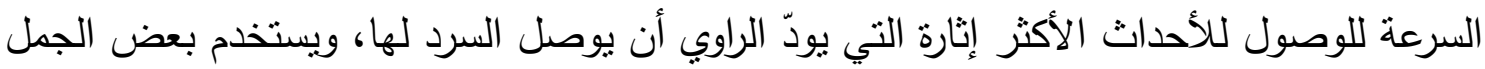

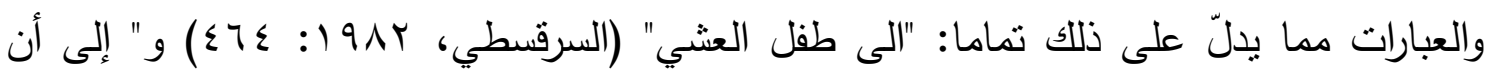

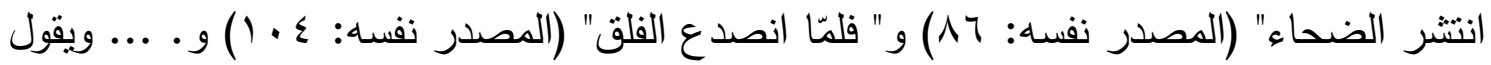

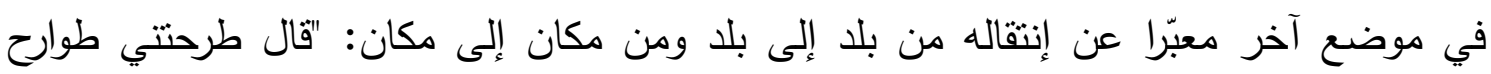

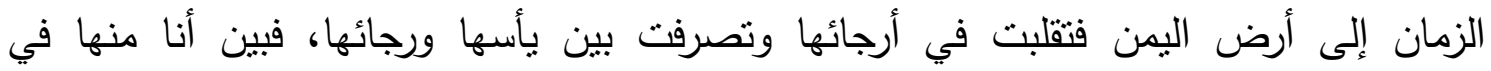

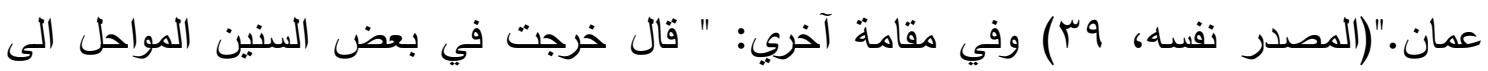
الأرياف والسواحل، فبين أنا أدور في ريف بعد ريف إذ وقعت الى جزيرة طريف"(المصدر نفسه، 
ع ك ). إن هذه العبارات تتقل السرد من حدث إلى حدث بأقصي سرعة له، حيث إنَّها تحذف مُدد

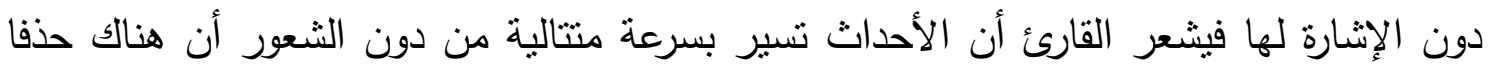

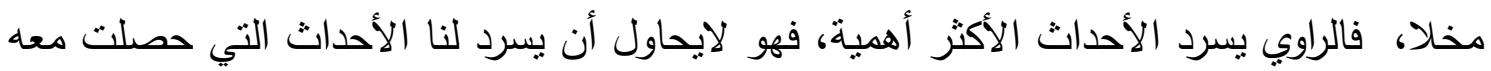

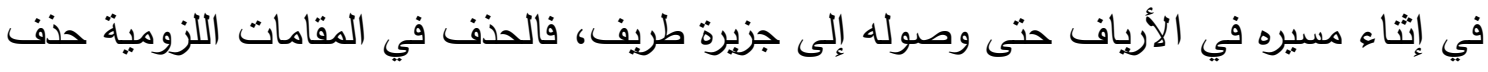

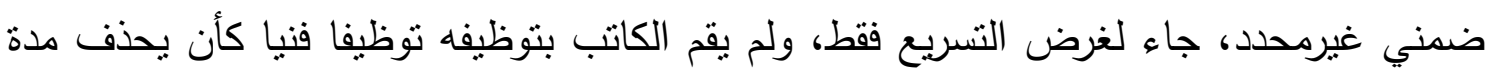

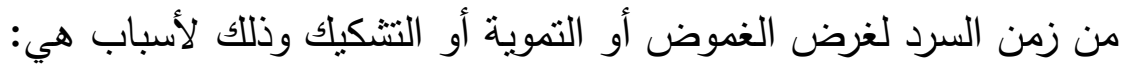

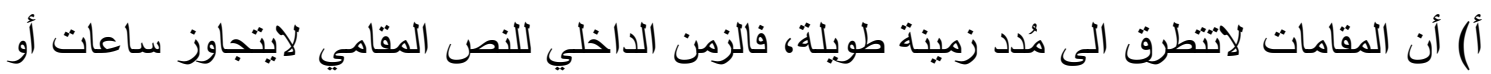

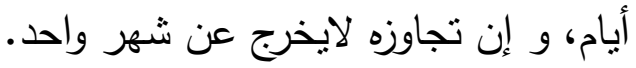

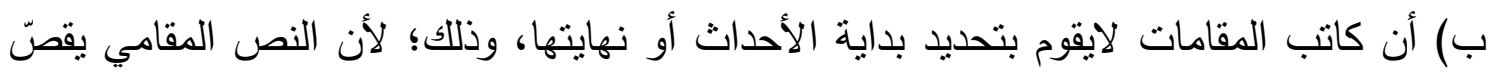

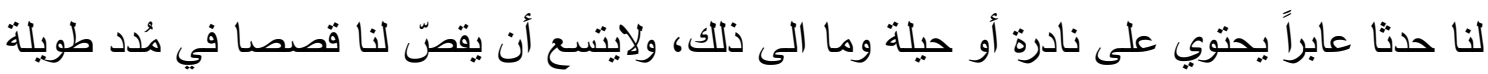
كالملاحم والرويات مما بستغرق عدة ساعات. ثنانيا/ التلخيص أو تقتية المجمل: ماكل

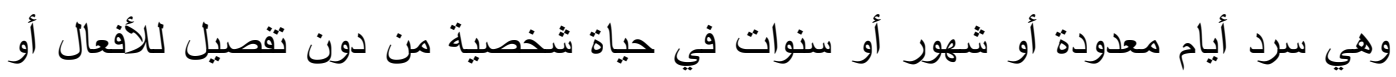

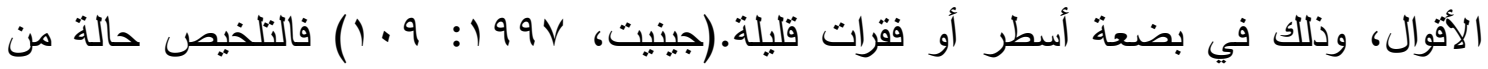
حالات تسريع السرد، ولكنها أقل سرعة من الحذف، فهو تلخيص حوادث عدة أيام أو عدة شهور

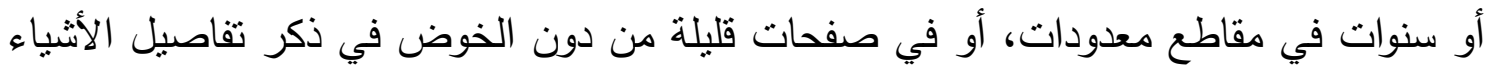

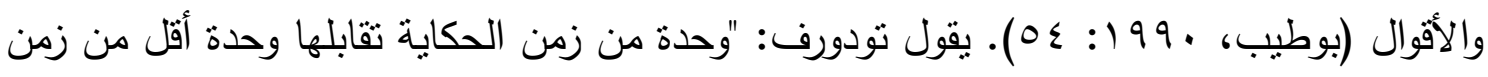

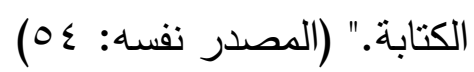
فهذه الثقنية تمدّنا بالمعلومات الضرورية عن الأحداث بأسلوب مركز ومكثّف، وذلك من الققز

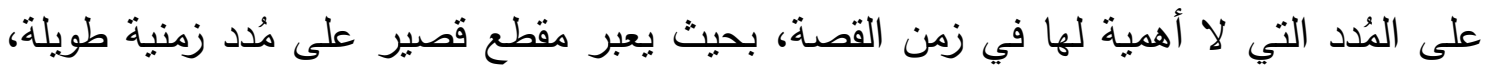

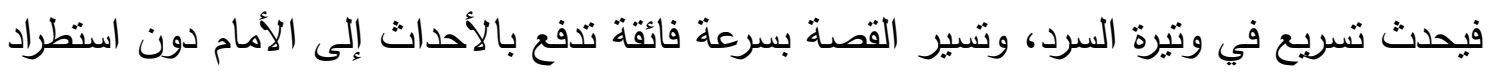

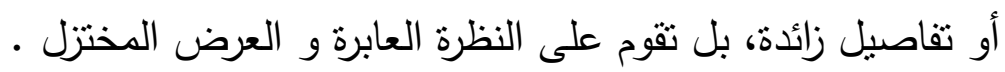

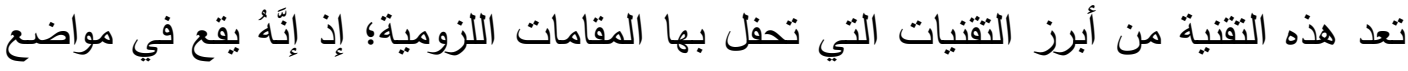

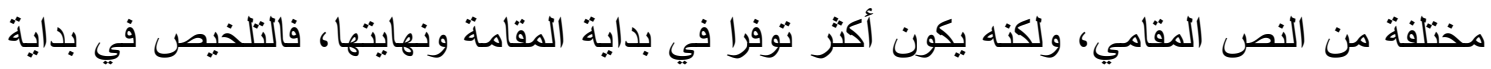

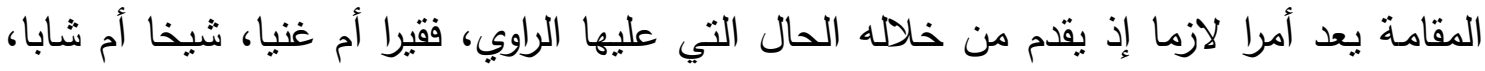

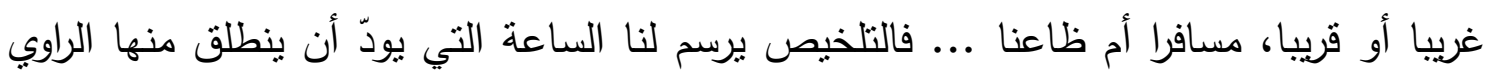
لأحداثه، وذلك عن طريق مروره على مُدد طويلة وصولا الى الحدث الذي يودّ الراوي أن يسردهـ...

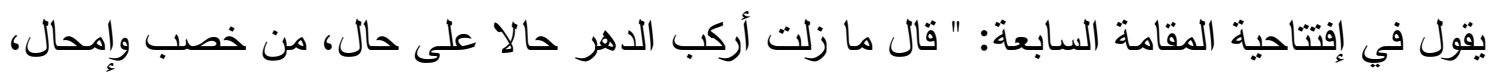
وحل وترحال، أتتبع الرزق وأستثيره، فيأبى عليّ قليله وكثيره، أقاربه فيباعد وأطالبه فلايساعد، 
فاستخرت الله تعالى على ركوب البحار وترك المهامة والصحار ، وقلت لعل ذلك أكثر جدوى وأقل

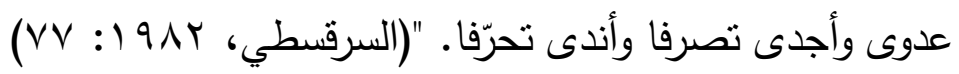
فحال الراوي متقلبة بين الخصب والإمحال، وهو دائم التتقل والترحال، طلبا للزرق، إذ إنه ممتتع عليه، فقرّر ركوب البحار لعله يجد الرزق الذي يريد، وذلك عن طريق مدينة مرقاة الثُحر

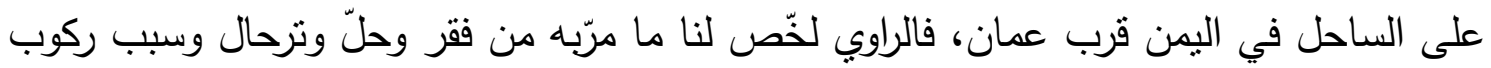

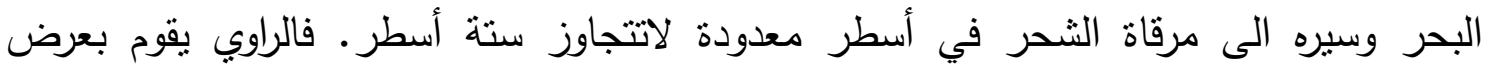

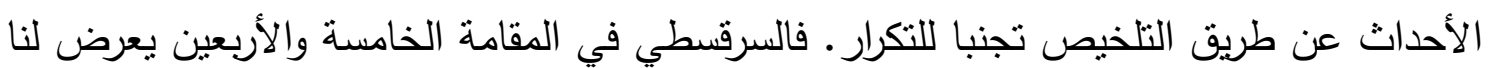
قصته مع الأسد ثم عرض لنا ما قام به الرعبان من ضيافة وتكريم عن طريق التلخيص، وذللك

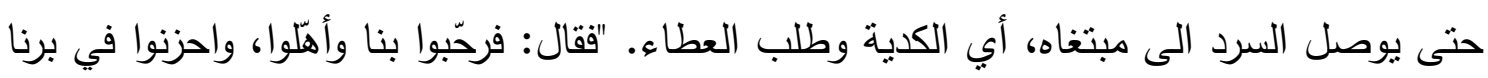
واسهلوا وبقينا عندهم دهرا طويلا، لانقدرعنه تحويلا، نأكل صفيف الثواء ونشرب حليب الدواء

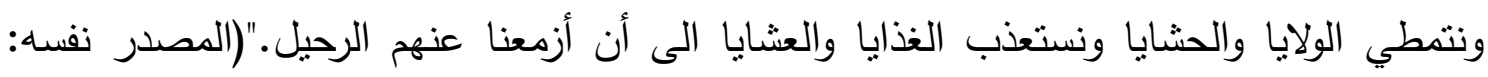

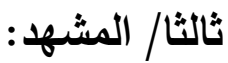

عبارة عن المقاطع الحوارية التي تأتي في تضاعيف السرد، مما تكسبه طابعا دراميا ومسرحيا "وهو ما ينعكس على مستوى القراءة في شكل إحساس بالمشاركة فيما يحدث"(بوطيب، •199: 00). وبتعبير آخر : هو اقتراب حجم النص القصصي من زمن الحكاية بحيث بطابقه

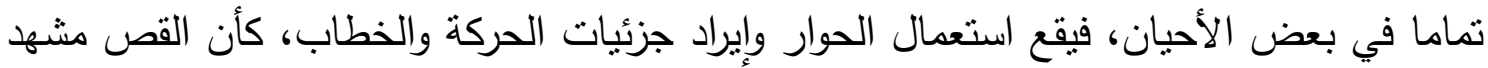

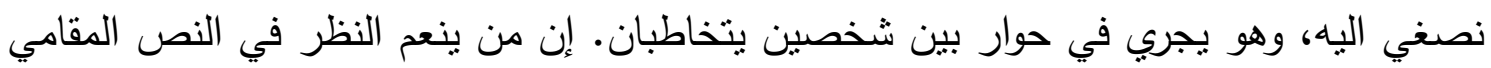
يجد أن السرد فيه ينراواح بين تقنيتين، هما: التلخيص والمشهد، حيث إننا نجد معظم المقامات

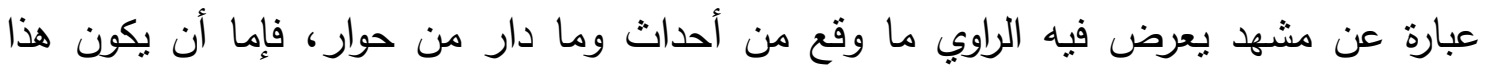

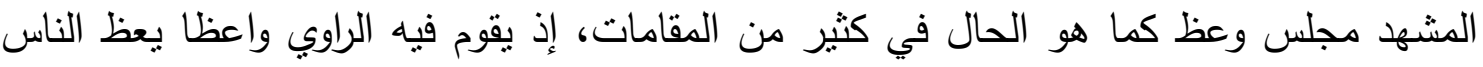
ويذكرهم باله، ولايكون هذا الوعظ وعظا مقصودا لذات الوعظ، وانما كان الهذف من ورائه الوصول

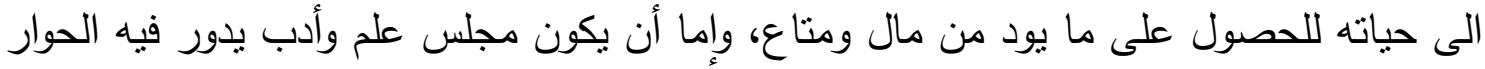

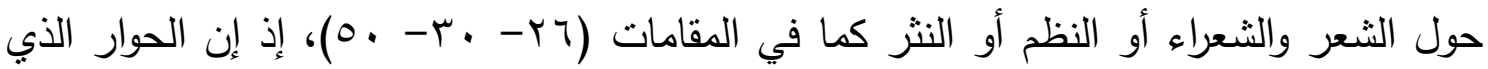

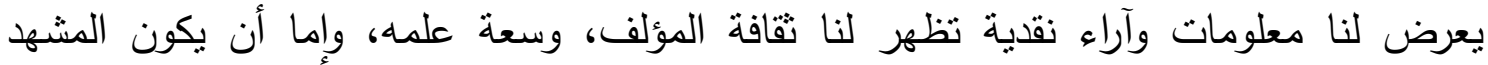

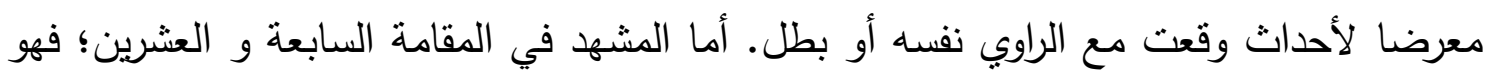

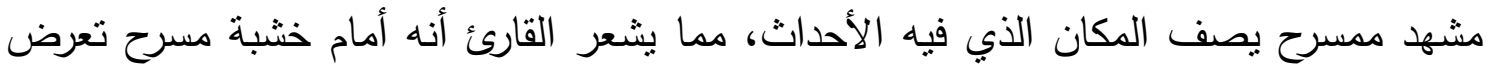

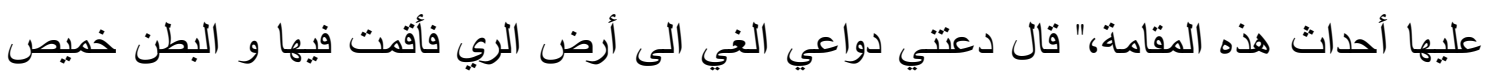
والثوب قميص، أعلم أني الغريب فأستريب، وأني الأسير فلا أسير، ألدح فلألأطمح وأسمع فلا 
أطمع، و للحر إحزان و إسهال، وللاهر إعجال و إمهال، إلى أن مررت بمسجد فيه ضجاج وجدال

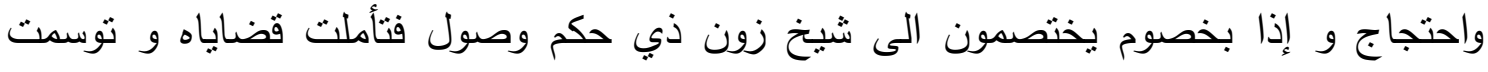

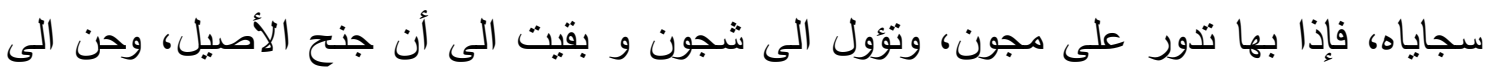

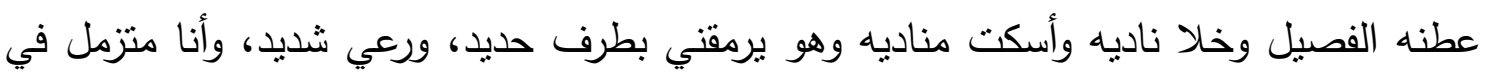

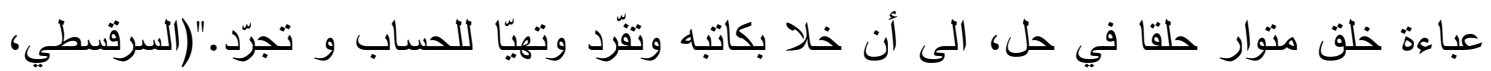

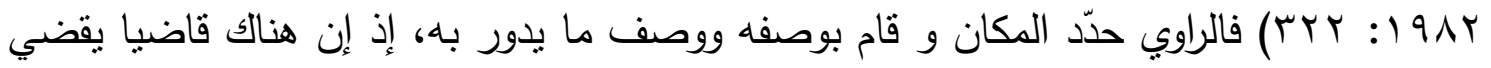

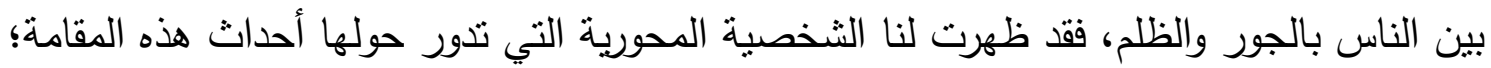

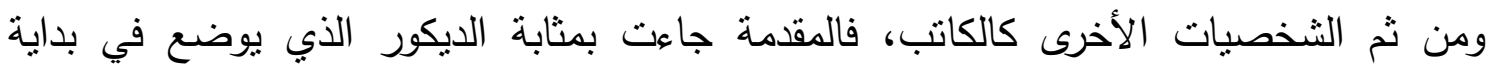

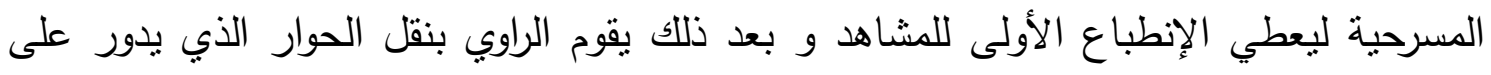

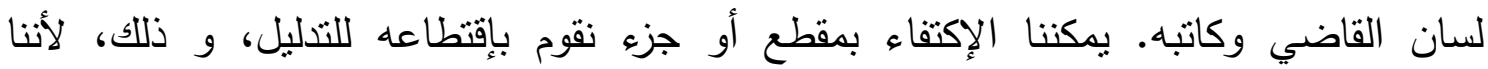
لانستطيع عرضه كاملا، إذ إنه مشهد حواري طويل نسبيا، بستغرق معظم المقامة:( وأرسل في

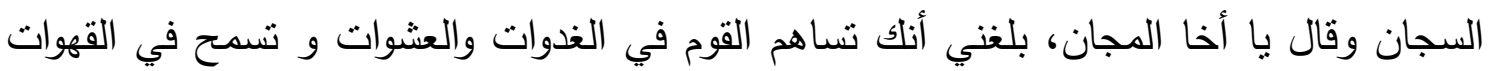

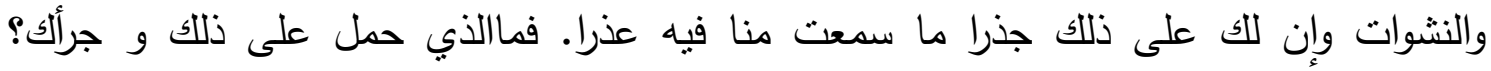
وخلصت من هذه التبعية و براك و هلا عرفنتا بما صنعت و أديت؟ ما جمعت و منعت تختص بها

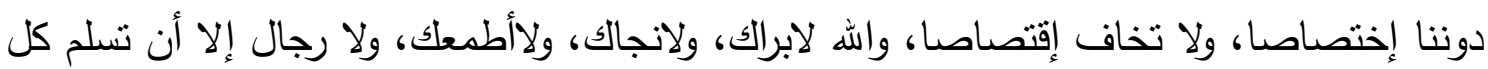

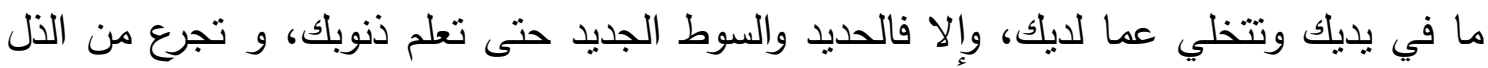

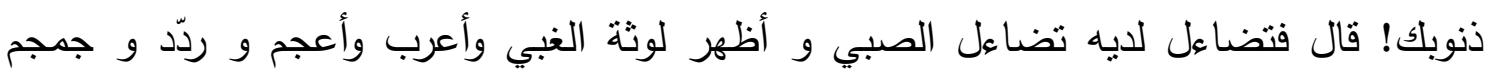

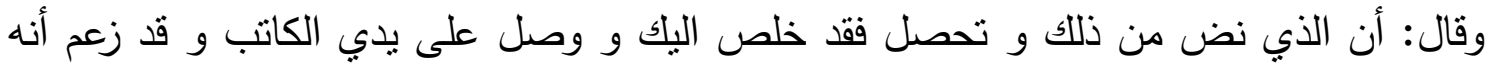

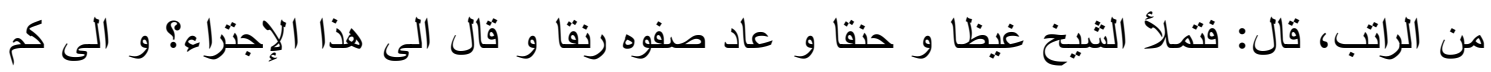

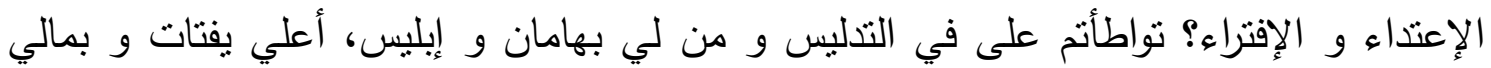

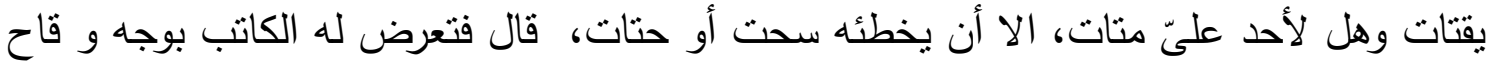
و عزم لقاح، وقال: إذا كنت تعني بالجليل و الحقير و تبحث عن الفتيل و النقير و تنكي علينا

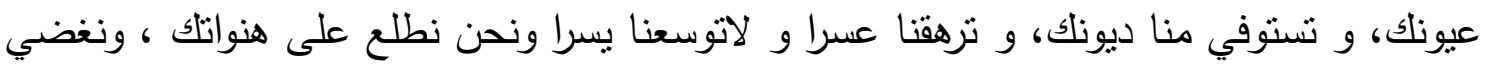

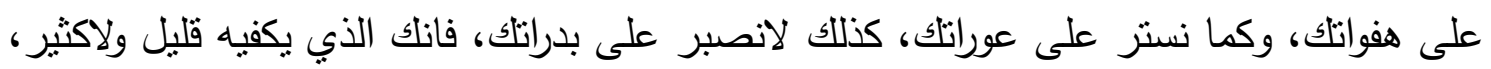

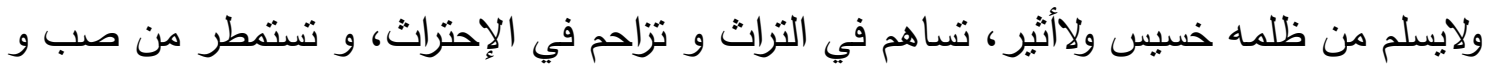

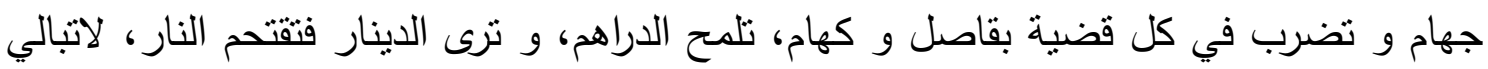

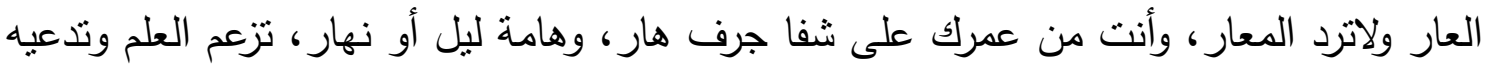

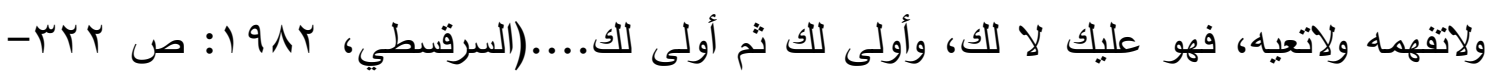


فنقف في هذا المشهد الحوراي على حوار خالص يدور بين شخصين، هما: القاضي، وكاتبه، مما يوحي بنوع من التوازن بين زمن الحكاية وزمن السرد، وقد جاء هذا الحوار ليساعد على تكوين صورة عن الثخصيات المتكلمة، والكثف عن طبائعها النفسية والإجتماعية والصراعات الخارجية لئاه الدائرة فيما بينها، نجد أيضا أن هذا الحوار حوار منقول على لسان الراوي مباشرة، إذ إنه نقل على الثى

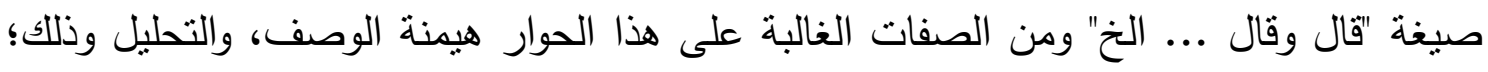

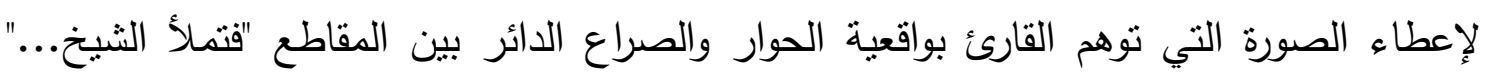

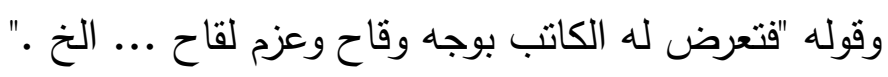

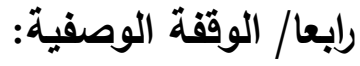

وهذه التقنية تعمل على إبطاء السرد ويحدث ذللك حين يلجأ الراوي إلى الوصف؛ لأنَّ

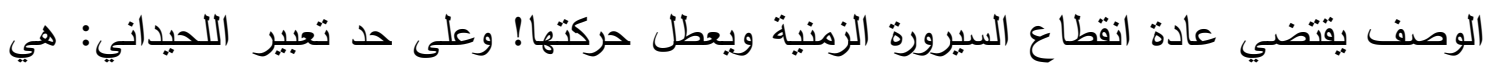

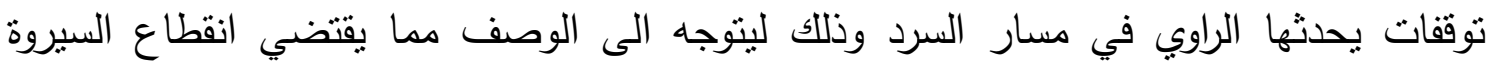

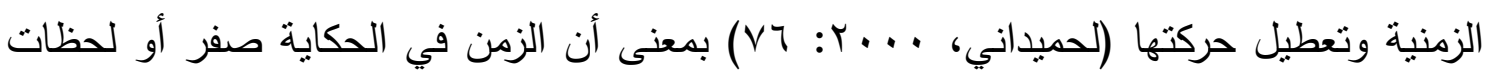
قصيرة وزمن السرد طويل على النقيض من الحذف، إن هذا النوع من النوقعات يقوم بوصف النفاء

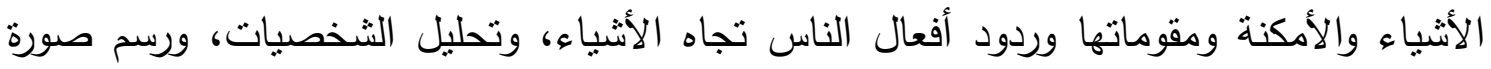

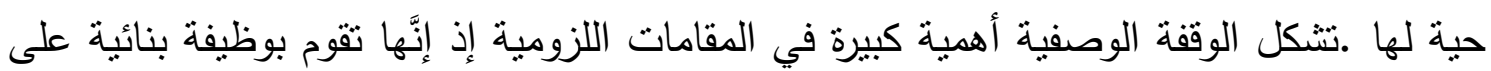

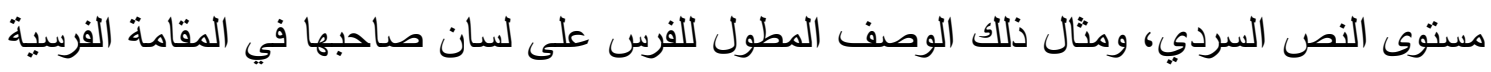

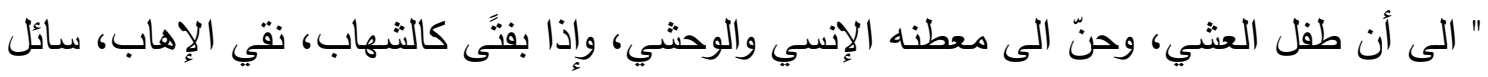

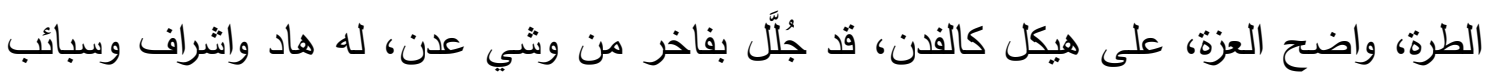

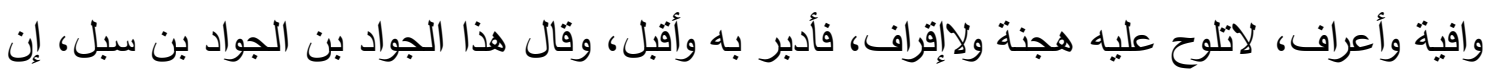

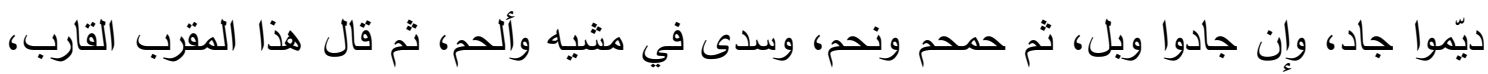

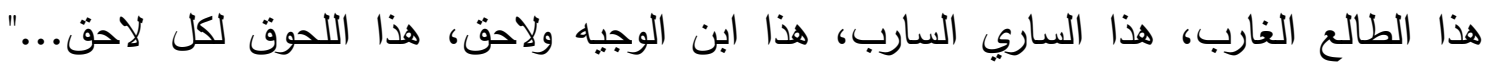

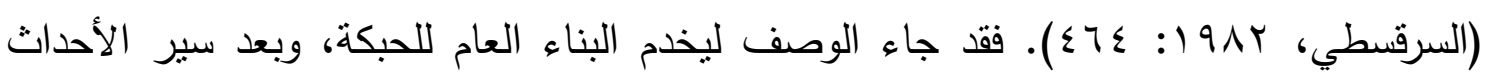

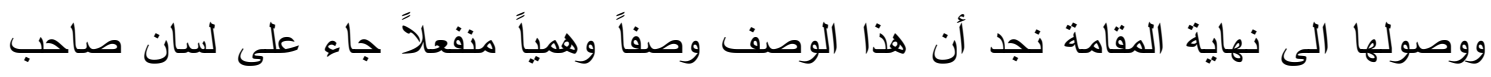

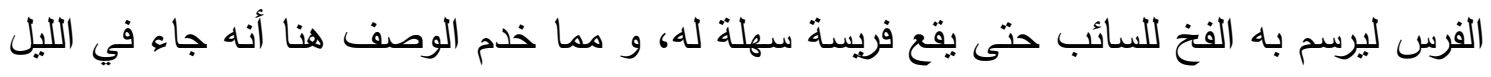

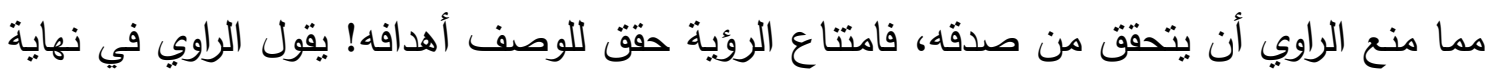

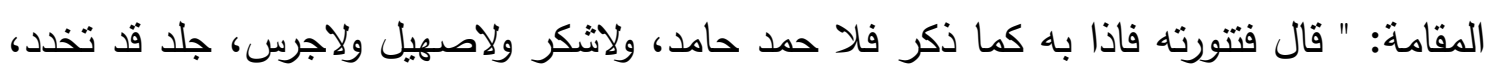

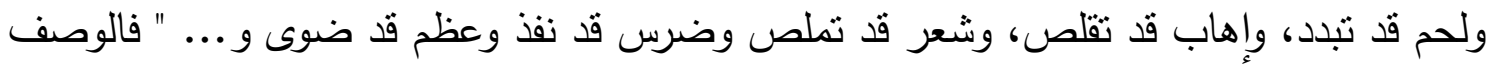

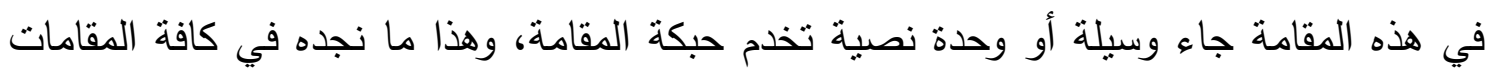

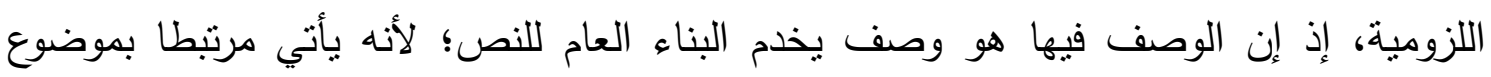


المقامة. ومما يواجهنا في هذا البحث صعوبة الفصل بين المقاطع الوصفية والسرد في بعض الدقامات، وذللك لامتزاج الوصف بالسرد، إذ إن النص الدقامي هو عبارة عن سرد وصفي يعمل

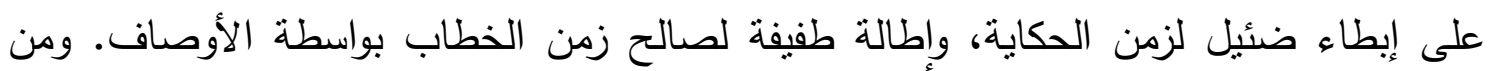

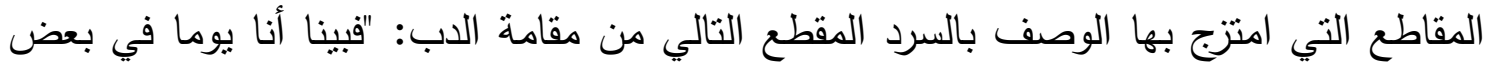

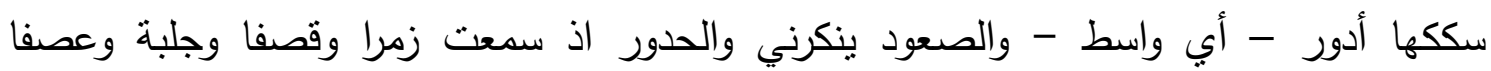
والولدان يتسابقون اليه تسابق الفراش ويتهارشون عليه أثند الهراش وهم يطيرون به عجبا ويطيلون

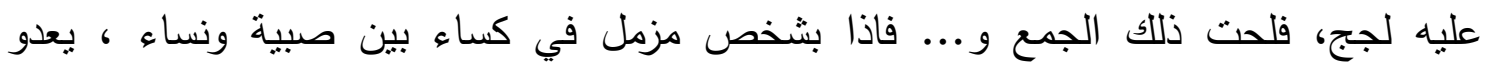
ويرقص، ويزيد في حديثه وينقص، وإذا في يده سلاسل، وحيوان كريه المنظر باسل، يرقص برقصه..." . فالمقطع الدذكور يكثف لنا عن امتزاج الوصف بالسرد امتزاجا عضويا، فتضافرهما

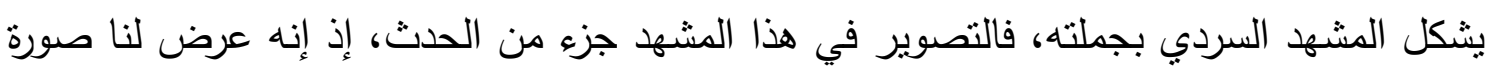
كاملة ذات طابع ذاتي يعبر عن رؤية الراوي لما يصف، وذلك كما في قوله: "واذا في يده سلاسل

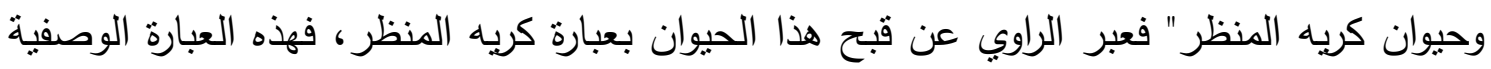
هي انطباع الراوي الذاتي عن الثيء المرئي الذي يصفه ـلقد تتاول الوصف في في الدقامات الأماكن

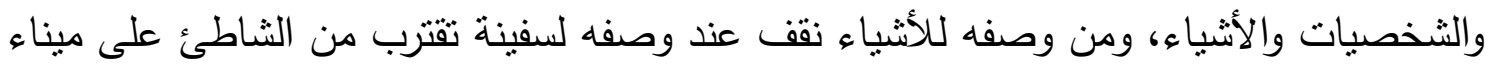

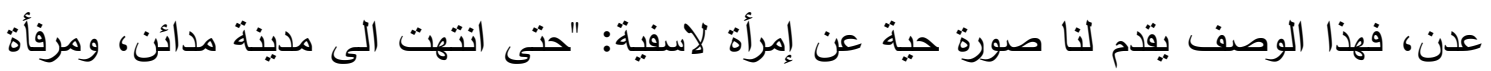

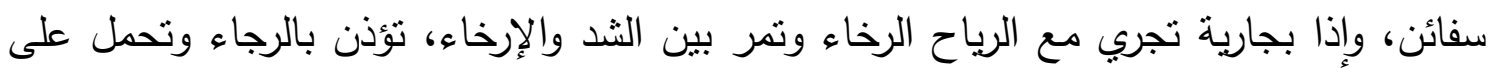

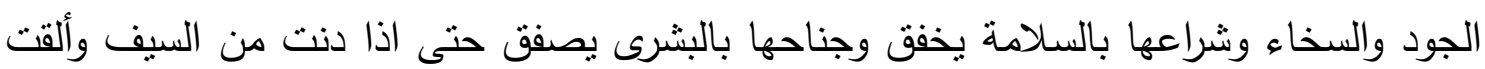

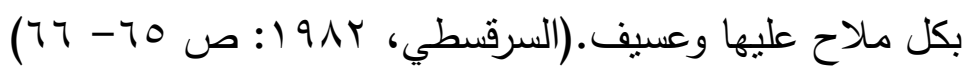
النتيجة:

نظرا لما ظهر في البحث فإنَّ عنصر الزمان من أهم العناصر ، التي ظهرت في المقامات

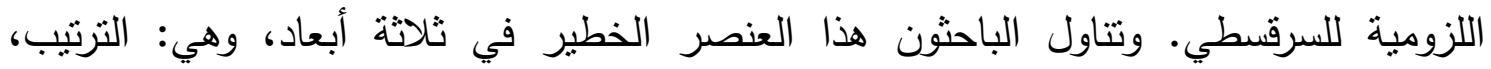
والديمومة، والتوالي. وتتخذ مقامات السرقسطي من حيث علاقات التزتيب حالة التوازن المثالي بمعنى أنها تتوالى على الورق كما هي على الواقع في أكثر من تسعين بالمائة من المقامات، ونأني

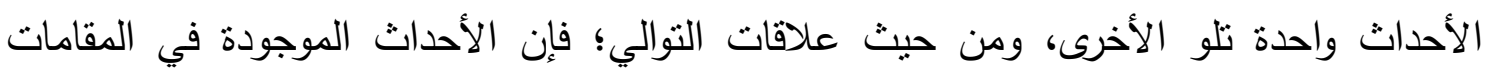
لاتتكرر في النص المقامي، وذللك؛ لضيق مساحة نص الدقامة وصغرها، فالراوي في الحقيقة يقص الاحس

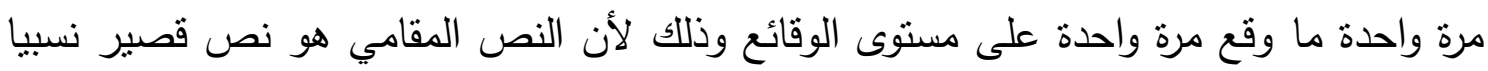
مقارنة بالفنون السردية الأخرى كالقصة والرواية، ولايتسع لتكرار الأحداث فيه أكثر من مرة واحدة،

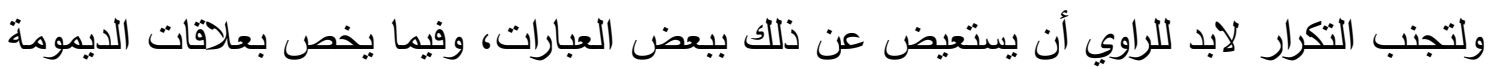

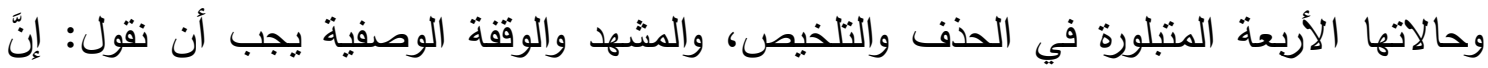


المقامات اللزومية مليئة بنلك الحالات الأربع، غير أن التلخيص والمشهد هما الأكثر ظهوراً في تلأك المقامات.

\section{المصادر والمراجي:}

1. ابن الابار، التكملة لكتاب الصلة، تحقيق إبراهيم الأبيارى، دارالكتاب اللبنانى، بيروت، 1919 م.

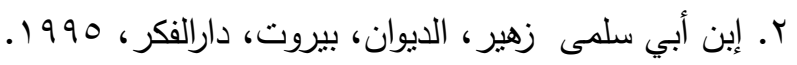

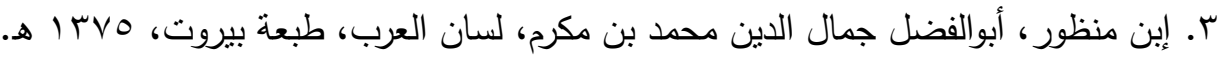

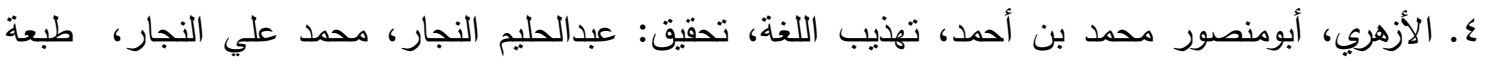

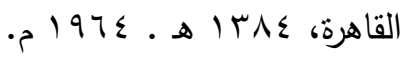
0. بحراوي حسين، بنية الثكل الروائي، الطبعة الأولى، .199. T. بوطيب، عبدالعالي، إنكالية الزمن في النص السردي، مكناس، ع V، ، ـ199.

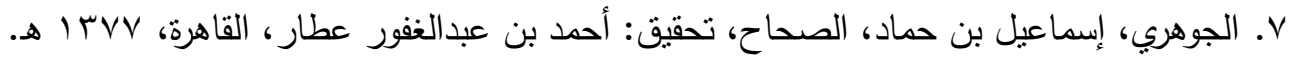
^. جينيت، جيرار، خطاب الحكاية، ترجمة محمد معتصم وآخرون، المجلس الأعلي للنقافة، الهيئة العامة لنثؤون المطابع الأميرية، الطبعة الثنانية، لو 199. 9. -حماد، احمد عبداللطيف، الزمان والمكان في قصة العهذ القديم، مجلة عالم الفكر ، الكويت، مج 17، عدد $.1910,70$ • 1. خليل شكري هياس، سيرة جبر الذاتية في البئر الأولى وشارع الأميرات، رسالة ماجستير، كلية التربية، جامعة

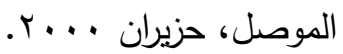
11. السرقسطي، أبوالطاهر محمد بن يوسف بن عبداله بن يوسف بن عبداله بن إبراهيم التميمي، الدقامات

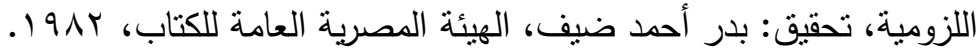
r ا. الزركلي، خيرالدين، الأعلام ، بيروت - لبنان، 1979.

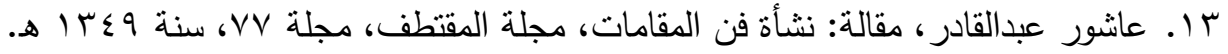
ـ ا. عباس إحسان، تاريخ الأدب الأندلسي عصر الطوائف والمرابطين، دارالثروق للنشر والتوزيع، الطبعة الثانية،

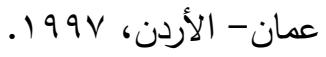

10 ا. عوض، يوسف: فن المقامات بين المشرق والمغرب، مكتبة الطالب الجامعي، مكة المكرمة، 1917 م. 17 العيد يمني، تقتيات السرد الروائي في ضوء المنهج البنيوي، دار الفاربي، الطبعة الثانية، ـ99.

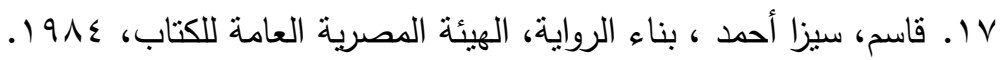
11. لحميداني حميد، بينة النص السردي من منظور النق الأدبي، بيروت- الحمراء، الطبعة الثالثة، ... بـ. 19 1. -مبروك، مراد عبدالرحمن، بناء الزمن في الرواية المعاصرة، الهيئة المصرية العامة للكتاب، 1991 ا. 


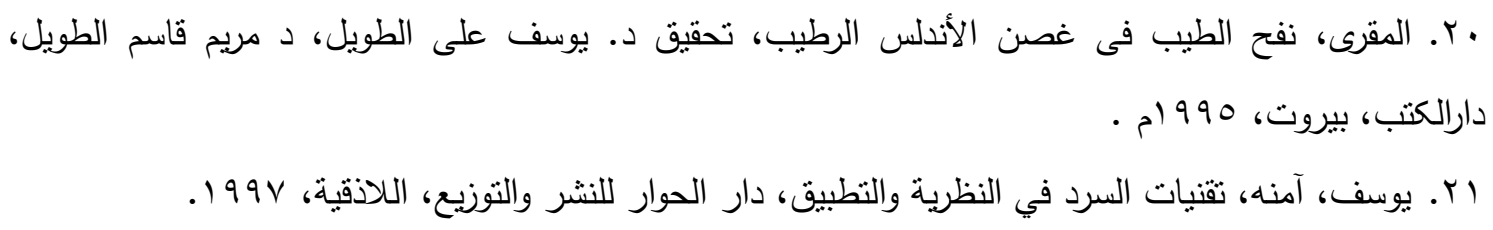

\section{Reference:}

1. Al-Azhari, Aboo-mansoor Mohammad ben Ahmad, Tahzib ALoghat, Tahghigh: Abolhalim Al-Najar,mohammad ali najar, Alghahera, 1384, 1964.

2. Ebn Abaar, Al-takmelat leketab Al-selat, Tahghigh: Ebrahim Abyari, Darolketab Al-Lobnani, Beirut, 1989.

3. Ebn Abi solmaa Zoheir, Al-Divan, Beirut, Darolfekr, 1995.

4. Ebn Manzoor, Abolfazl Jamalodin Mohammad ebn Mokarram, Lesanol Arab, Taba'at Beirut, 1375.

5. Bahravi Hossein, Boniate shekel Revaei, First Edition, 1990.

6. Boo Tayyeb, AbdolAali, Eshkaliat Al-zaman fi Nassel sardi, Meknas, 1990.

7. Al-johari, Esmaeel ben hammad, Al-sehah, Tahghigh: Ahmad ben Abdolghafoor attar, Alghahera, 1377.

8. Jinit jirar, khetab Al- hekaiat, translate: Mohammad motasam and ..., Al majlesel A'ala lelsaghafat, Al- heiatel amat leshounel Matabe Al- Amiriat, second edition, 1997.

9. Hammad, ahmad abdollatif, azaman va al-makan fi ghesatel ahdel ghadim, j. Alem Al-fekr, Kuwait, No. 65, 1985.

10. Khalil shokri hias, sirat jabr Al-zatiat fi Al-Be'er Al-oola va share Al-amirat, M.S. Thesis, koliat al-tarbiat, jame moosel, Hazizan, 2000.

11. Al-sarghasti, Abo Al-taher mohammad ben yuosof ben abdollah ben yuosof ben abdollah ben Ebrahim altamimi, Al-maghamat Al-lzoomiat, Tahghigh: badr ahmad zeif, alheiat almesriat alamat lelketab, 1982.

12. Al-zerekli, kheirodin, Alalam, Beirut - Lebanon, 1969.

13. Ashoor Abdolghader, J. kashat fan al-maghamat, majalat Al-Moghtataf, Majalat 77, 1349.

14. Abbas Ehsan, Tarikh adab Andolosi asr Al-tavaef va Al-morabetin, Dar-Alshorugh, second edition, oman, Alordon, 1997.

15. Avaz yoosof, fan Al-maghamat bein al_mashregh va Al-maghreb, Al-taleb Aljamei, Mecca, 1986. 
16. Al-eid yamani, Taghaniat al-sard Al-alrevae fi zoe Al-manhaj Al-bonyavi, Darolfarebi, second edition, 1990.

17. Ghasem siza ahmad, Banao Al-revaiat, Al-heiat Al-mesriat Al-amat lelketab, 1984.

18. Lahmidani hamid, Boniat Al-nas Al-sardi men manzoor Al-naghd Al-adabi, Beiruthamra, third edition, 2000.

19. Mabrook Morad Abdorahman, banao Al-zaman fi Al-revaiat Al-moaserat, Alheiat Almesriat Akamat, 1998.

20. Al-moghri, Nafh Al-tayeb fi ghosne andolos Al-ratib, Tahghigh: Dr. yoosof Ali Altavil, Dr. Maryam ghasem Al-tavil, Darolkotob, Beirut, 1995.

21. Yoosof Amene, Taghaniat Al-sard fi Al-nazariat va Al tatbigh, Darol hevar, Lattakia, 1997. 